\title{
Physical exercise, energy expenditure and tobacco consumption in adolescents from Murcia (Spain)
}

\author{
Pedro Luis Rodríguez García, M.D. , ${ }^{a}$ Francisco José López Villalba, M.D., ${ }^{a}$ \\ Pedro Angel López Miñarro, M.D., " and Eliseo García Cantó, M.D. ${ }^{a}$
}

\begin{abstract}
Introduction. Physical and sports activity is essential for a healthy lifestyle and is considered a prevention factor for several harmful habits on health. The purpose of this study was to establish the relationship between the level of physical activity, energy expenditure and tobacco consumption among adolescent students.

Population and Methods. Adolescent students aged 14 to 17 years old from the province of Murcia were included. Their level of physical activity was assessed using the International Physical Activity Questionnaire, and smoking was evaluated using the Youth Risk Behavior Surveillance.

Results. Out of 344 adolescents, 20.3\% were overweight and $5.8 \%$, obese. Of the total, $44.2 \%$ reported being active on a regular basis, while $55.8 \%$ were irregularly active or inactive. The level of physical exercise was higher among boys than girls. Tobacco was consumed by $20.3 \%$ of the sample, but no significant differences were observed based on sex. The highest energy expenditure from physical activity was positively associated with non consumption of tobacco. Conclusions. Among adolescents, a higher level of physical activity and a higher energy expenditure are positively associated with non consumption of tobacco.

Key words: physical activity, energy expenditure, tobacco, obesity, students.
\end{abstract}

http:/ /dx.doi.org/10.5546/aap.2014.eng.12

a. School of Education, Area of Didactics of Physical Expression, Department of Dynamics, Musical and Artistic Expression, Universidad de Murcia, Espinardo Campus, Espinardo.

E-mail Address:

Francisco José López Villalba, M.D.: paco.lopez@um.es

Conflict of interest: None.

Received: 4-13-2013 Accepted: 7-29-2013 asthma, and increased predisposition to infections. ${ }^{3}$

Adult obesity has been related to childhood and adolescence weight. ${ }^{4}$ Although it may have a genetic influence, certain behaviors like a sedentary lifestyle and an unbalanced diet are key factors for adolescent obesity. ${ }^{5}$

Several studies have analyzed obesity in the adolescent population..$^{6-8}$ In addition, the increasing consumption of tobacco among youth has raised great public concern over the past years. Although different studies have shown a positive relationship between tobacco consumption and the risk of eating disorders among adolescents, ${ }^{9,10}$ and lower body mass indexes than non smokers, ${ }^{11-13}$ such relationship can be triggered by other reasons. Investigations on tobacco consumption have confirmed the establishment and development of this legal drug, which has progressively become consolidated as a harmful life habit among adolescents. ${ }^{6}$ However, the National Student Survey (State Survey on the Use of Drugs in Secondary Education, ESTUDES) ${ }^{14}$ found a reduction of tobacco consumption in adolescent students compared to the data collected in the prior survey.

With respect to such problems faced by adolescents, we believe that adopting an active lifestyle with regular physical exercise is associated with a reduced consumption of toxic substances, including tobacco. ${ }^{15-17}$

Continuous physical activity, together with a balanced diet, contributes to an adequate regulation of body weight and makes the onset of obesity more difficult, both during childhood and adulthood $(80 \%$ of 
obese adults were obese children). ${ }^{18}$ Besides, systematic physical exercise has been related to the prevention of metabolic and cardiovascular conditions. ${ }^{18}$ According to the AVENA study, ${ }^{6}$ inactivity poses a health risk factor. Different studies have demonstrated a relationship between a low level of physical activity and increased body mass index in adolescents. ${ }^{19,20}$ For this reason, physical exercise is considered a basic protective element against obesity, especially the practice of mainly aerobic activities. ${ }^{21}$

The objectives of this study were: 1) to determine the levels of extracurricular physical activity and energy expenditure; 2) to analyze the frequency of tobacco consumption; and 3) to determine the association between the level of physical activity done out of school and tobacco consumption among adolescent students from the province of Murcia.

\section{POPULATION AND METHODS Population}

In a population of 5400 adolescent students aged 14-17 years old, a randomized sample was selected out of different school facilities from various locations in the North of the province of Murcia. Selection was based on a stratified and multiple stage process with different sampling units (regions, municipalities, school facilities). Subjects participated in the study from January to May of 2011. Sample selection was based on a $95.5 \%$ confidence interval and a margin of error of the estimate $\pm 5.2 \%$. The sample was selected out of all students enrolled at $3^{\text {rd }}$ and $4^{\text {th }}$ grades of Obligatory Secondary Education (OSE) and at $1^{\text {st }}$ grade of High School.

\section{Procedure}

The study was approved by the Ethics Committee of Universidad de Murcia. Before data collection, permission was obtained from school authorities. In addition, study procedures were informed to parents and students, and their informed consent was obtained.

Questionnaires were self-administered in small groups ( 25 to 30 students) and adolescents had to complete the items proposed themselves. The process was conducted under the supervision of an investigator.

The International Physical Activity Questionnaire ${ }^{22}$ was used to assess the level of physical activity performed.

This questionnaire measures the level of physical activity done by adolescents out of school and is made up of 4 items. Based on data collected, adolescents were classified into one of the following three categories: inactive (no physical exercise), irregularly active (some sort of physical exercise one to three times a week), and regularly active (physical exercise more than three times a week).

Supported by data obtained in the questionnaire, the weekly energy expenditure was determined (measured in metabolic equivalents / day, MET) using the compendium of energy expenditure associated to different activities. ${ }^{23}$

The Youth Risk Behavior Surveillance, ${ }^{24}$ an opinion questionnaire regarding the habit of tobacco consumption in adolescents was used to assess tobacco consumption. It included qualitative, dichotomous and polychothomous items, as well as hierarchical items, to evaluate if adolescents had ever used tobacco, age at initiation and usual consumption. Terms were culturally adapted and the questionnaires were translated from English into Spanish according to the International Test Commission (ITE) recommendations for test design and adaptation..$^{25,26}$

Finally, a 13 item questionnaire was prepared (4 items in relation to physical exercise, 4 items regarding tobacco consumption and 5 items associated with general matters). The questionnaire was first cognitively pretested with a pilot sample of 99 adolescents (41 girls and 51 boys) so as to determine the level of comprehension of the different items, the time required to administer it and any complication with its implementation.

The pilot test results indicated to remove certain items and modify how others were stated. Once corrections were made, the definite version of the questionnaire was prepared and self-administered by participants (Annex 1, digital version).

Following the questionnaire administration, height and weight were recorded using a scale and stadiometer (Quirumed model 0072e) with adolescents barefoot and wearing light clothing. For height measurement, they stood standing in the stadiometer. Height was recorded to the nearest millimeter.

Based on height and weight data, their body mass index (BMI) was determined by dividing weight in kilograms by the square of height. Results were categorized into four groups (low weight, normal weight, overweight, obesity) according to international standard cut-off points. ${ }^{27}$ 
Such cut-off points were established for children and adolescents aged 2 to 18 years old, by sex, with 0.5 points per year and the following values as reference: $<18.5 \mathrm{~kg} / \mathrm{m}^{2}$, low weight; $>25 \mathrm{~kg} / \mathrm{m}^{2}$, overweight; and $>30 \mathrm{~kg} / \mathrm{m}^{2}$, for obesity.

\section{Data Analysis}

Descriptive statistics were obtained using, for categorical outcome measures, numeric and percentage count according to the sample's sex and age. For continuous outcome measures, mean, median and standard deviation values were expressed. Student's $t$ test was used for independent samples to determine differences between sexes.

The relationship between categorical outcome measures was determined using contingency tables and Pearson's $\chi^{2}$ test with the corresponding residual analysis (with $p<0.05$ considered a significant value). Inferential statistics were developed using an analysis of variance (ANOVA) so as to study the relationship between tobacco consumption and energy expenditure in adolescents based on their sex.

\section{RESULTS}

The definite sample was made up of 354 subjects. All students in the classroom on the day of the questionnaire were surveyed. Out of this sample, 10 adolescents $(2.9 \%)$ were excluded because they did not complete the questionnaire correctly. Out of the total sample, $20.3 \%$ were overweight and $5.8 \%$ were obese, with no significant differences observed in terms of gender. Table 1 shows the sample characteristics. Of all participants, $54.95 \%$ were boys and $45.05 \%$, girls. The $t$ test for independent samples showed no differences in body mass index by sex. On the contrary, significant differences were observed in weight, height and energy expenditure values.

Data indicate that $80.4 \%$ of boys did physical exercise versus $58.1 \%$ of girls (Table 2 ).

The $\chi^{2}$ test demonstrated that males were significantly more active than females $(p=0.000)$. Conversely, $29.7 \%$ of adolescents were physically inactive $(19.6 \%$ of boys and $41.9 \%$ of girls).

Regular tobacco consumption was referred by $20.3 \%$ of adolescents (Table 3 ), with no significant differences between genders $(19 \%$ of boys vs. $21.9 \%$ of girls).

Both male and female adolescents considered active were associated with rejection of tobacco consumption (Table 4 ). The $\chi^{2}$ test was complemented with the residual analysis and it showed a significant relationship between a regular physical activity and tobacco consumption both in males and females.

TABLE 1. Sample characteristics by sex

\begin{tabular}{lcccc}
\hline & Total & Male & Female & t $(p$ value $)$ \\
\cline { 2 - 5 }$n$ & 344 & 189 & 155 & \\
Weight in kg, mean (standard deviation) & $63.73(13.236)$ & $66.91(14.145)$ & $59.85(10.879)$ & $26.027(0.000)$ \\
Height in cm, mean (standard deviation) & $133.46(65.968)$ & $140.63(64.478)$ & $124.72(66.911)$ & $5.015(0.026)$ \\
BMI, mean (standard deviation) & $23.05(3.990)$ & $22.99(4.226)$ & $23.13(3.693)$ & $0.085(0.771)$ \\
Energy expenditure in kcal/week, & & & & \\
mean (standard deviation) & $1396.57(1744.334)$ & $1972.41(1834.196)$ & $694.42(1329.182)$ & $52.586(0.000)$ \\
\hline
\end{tabular}

BMI: Body mass index.

TABLE 2. Level of physical activity by sex

\begin{tabular}{lcccc}
\hline & Total & Inactive & $\begin{array}{c}\text { Physical activity } \\
\text { Irregularly active }\end{array}$ & Regularly active \\
\hline Total n (\%) & $344(100)$ & $102(29.7)$ & $90(26.2)$ & $152(44.2)$ \\
Male n (\%) & $189 / 344$ & $37(19.6)$ & $47(24.9)$ & $105(55.6)$ \\
CTR & $(54.9)$ & -4.5 & -0.6 & 4.7 \\
Female n (\%) & $155 / 344$ & $65(41.9)$ & $43(27.7)$ & $47(30.3)$ \\
CTR & $(54.1)$ & 4.5 & 0.6 & -4.7 \\
\hline
\end{tabular}

CTR: corrected typified residuals: $\chi 2: 26.898 ; p=0.000$. 
For boys, it was positively associated with those categorized as regularly active $(p=0.05)$. For girls, it was associated with those categorized as irregularly active $(p=0.01)$.

Mean weekly energy expenditure values in relation to tobacco consumption in adolescents and by sex are presented in Table 5 . The analysis of variance showed a significant relationship between weekly energy expenditure and tobacco consumption among boys $(p=0.031)$. Male adolescents with a higher energy expenditure smoked less, and these data were confirmed by the Student's $t$ test value $(-5,11)$ and by the size of the relationship with a $R=0.65$. Such relationship was not observed among girls.

TABLE 3. Tobacco consumption by sex

\begin{tabular}{lccc}
\hline & Total & \multicolumn{2}{c}{ Tobacco consumption } \\
& & Smoker & Non smoker \\
\hline Total $n(\%)$ & $344(100)$ & $70(20.3)$ & $274(79.7)$ \\
Boy $n(\%)$ & $189 / 344$ & $36(19)$ & $153(81)$ \\
CTR & $(54.9)$ & -0.7 & 0.7 \\
Girl $n(\%)$ & $155 / 344$ & $34(21.9)$ & $121(78.1)$ \\
CTR & $(54.1)$ & 0.7 & -0.7 \\
\hline
\end{tabular}

CTR: corrected typified residuals; $\chi^{2}: 0.438 ; \mathrm{p}=0.298$

\section{DISCUSSION}

The purpose of this study was to establish the relationship between the level of physical activity, energy expenditure and tobacco consumption among adolescent students.

Regarding the level of physical exercise, results show that $44.2 \%$ of participants can be categorized as physically active (doing exercise more than 3 times a week) and that most of these were boys (55.6\% of boys vs. $30.3 \%$ of girls).

By comparison, these data are similar to those obtained in the OPACA study ${ }^{28}(74 \%$ of exercise practice) and those detailed by Thibault, et al., ${ }^{29}$ which indicated that $73.8 \%$ of adolescents did physical activities $(80.8 \%$ of men and $66.8 \%$ of women).

However, these values are higher than those obtained in other studies. For example, the AVENA study ${ }^{6}$ found that $59.2 \%$ of adolescents were considered physically active $(71.1 \%$ of boys and $46.7 \%$ of girls). Villagrán, et al. ${ }^{30}$ observed a physical activity index of $58.8 \%$ (71.7\% among boys and $46 \%$ among girls). Likewise, Robles, et al. ${ }^{31}$ demonstrated that $61.7 \%$ of adolescents stated to have done some kind of physical activity out of school ( $78.8 \%$ of boys and $44.6 \%$ of girls).

Although there are other studies that have

TABLE 4. Association tests (Pearson's $\chi^{2}$ complemented with a residual analysis) that relate regular physical exercise with tobacco consumption

\begin{tabular}{|c|c|c|c|c|c|c|c|c|c|c|c|}
\hline \multirow{2}{*}{\multicolumn{2}{|c|}{$\begin{array}{l}\text { Related } \\
\text { outcome }\end{array}$}} & \multicolumn{5}{|c|}{$\begin{array}{c}\text { Male } \\
\text { Regular smoker }\end{array}$} & \multicolumn{5}{|c|}{$\begin{array}{c}\text { Female } \\
\text { Regular smoker }\end{array}$} \\
\hline & & Yes (n/\%) CTR & No (n/\%) CTR & Total & $\chi^{2}$ & $\mathrm{p}$ & Yes (n/\%) CTR & No $(n / \%)$ CTR & Total & $\chi^{2}$ & p \\
\hline \multirow{4}{*}{ 总 } & Inactive & $12(6.3 \%) 2.3$ & $25(13.2 \%)-2.3$ & 37 & & & $23(14.8 \%) 3.4$ & $42(27.1 \%)-3.4$ & 65 & & \\
\hline & $\begin{array}{l}\text { Irregularly } \\
\text { active }\end{array}$ & $9(4.8 \%)-0.0$ & $38(20.1 \%) 0.0$ & 47 & 5.843 & 0.050 & $2(1.3 \%)-3.2$ & $41(26.5 \%) 3.2$ & 43 & 14.581 & 0.001 \\
\hline & $\begin{array}{l}\text { Regularly } \\
\text { active }\end{array}$ & 15 (7.9\%) -1.9 & $90(47.6 \%) 1.9$ & 105 & & & $9(5.8 \%)-0.6$ & $38(24.5 \%) 0.6$ & 47 & & \\
\hline & Total & 36 & 153 & 189 & & & 34 & 121 & 155 & & \\
\hline
\end{tabular}

$\mathrm{N}$ : subject frequency; \%: percentage; CTR: corrected typified residues.

$\chi^{2}$ : Pearson's chi-square.

TABLE 5. Relationship between weekly energy expenditure from physical exercise and tobacco consumption

\begin{tabular}{lcccccccccc}
\hline \multicolumn{10}{c}{ Weekly energy expenditure } \\
\hline Related outcome & $\mathbf{n}$ & Mean & $\mathbf{F}$ & $\mathbf{t}$ & $\mathbf{p}$ & $\mathbf{n}$ & Mean & $\mathbf{F}$ & $\mathbf{t}$ & $\mathbf{p}$ \\
\hline Smoking & 36 & 1381.4 & & & & 34 & 842.03 & & 0.46 \\
No smoking & & & 4.708 & -5.11 & 0.031 & & & 0.536 & 0.732 \\
\hline
\end{tabular}

Energy expenditure: kcal/week; F: Snedecor's statistics. 
analyzed the level of physical activity in Spanish adolescent students, ${ }^{6,28,32}$ the use of different methodologies renders the possibility of a comparison difficult. ${ }^{8}$

Another outcome measure analyzed in this study was tobacco consumption. Data indicate that $23 \%$ of the surveyed adolescents smoked regularly (smoking at least one cigarette in the past 7 days), with a slightly higher consumption observed among girls, although no significant difference was observed from boys.

The National Student Survey ${ }^{14}$ shows a trend towards the reduction of tobacco consumption among students; $32.4 \%$ of adolescents had smoked in the past 12 months. Our data indicate lower values than those obtained by Mulassi, et al. ${ }^{33}$ who observed that $29.3 \%$ of students had smoked in the past month (25.2\% of boys compared to $32.6 \%$ of girls).

The BMI was used in order to establish the presence of overweight or obesity.

Our data indicate that $20.3 \%$ of adolescents were overweight, while $5.8 \%$ were obese, with no significant differences observed in terms of gender. These data are consistent with those of the studies by Villagrán, et al., ${ }^{30}$ who found that $28.6 \%$ of students were obese ( $24.4 \%$ of boys and $32.9 \%$ of girls). However, these data are slightly lower than those obtained in the study by Martínez, et al., where $30.5 \%$ of students were found to be obese, and than those indicated by an international study conducted in 34 countries in $2005,{ }^{34}$ where the data corresponding to Spain established that $29 \%$ of adolescents were obese. As a matter of fact, the data obtained in this study indicate higher values than those obtained among French adolescents, ${ }^{29}$ with $13.6 \%$.

The analysis of the relationship between doing physical exercise and consuming tobacco in adolescents found a trend to non smoking among those who were physically active. In accordance with national ${ }^{8,30}$ and international ${ }^{16,17}$ studies, active adolescents smoke less. In this study, 85.9\% of active adolescents indicated that they did not smoke, compared to $66 \%$ of non active adolescents. In this sense, Aleixandre, et al., ${ }^{15}$ (2005) found that adolescents who stated doing sports had a 59\% lower consumption of tobacco than those who did no physical exercise, i.e., a tobacco consumption 20 times lower in terms of number of cigarettes smoked per week.

Lastly, Halperin, et al., ${ }^{17}$ (2010) found that in a study with 10000 American university students, any level of tobacco consumption was associated with a lower level of physical activity. University students who used to do physical exercise three or more times a week smoked less than those who did so less than three times a week.

A relevant aspect of this study is the difference found when analyzing energy expenditure of adolescents and their relationship with tobacco consumption. Accordingly, it has been observed that physically active adolescents are associated with non smoking. However, such relationship is not evident among girls. In this sense, we observed how other studies ${ }^{6,10,13,15}$ that investigated the relationship between physical exercise and tobacco consumption did not analyze the energy expenditure of such exercise in adolescents. Our data indicate that adolescents students associated with non smoking had a higher energy expenditure than those who did smoke. In this regard, no significant difference was found by Bradley, et al. ${ }^{13}$ (2010) regarding total energy expenditure when comparing male and female adults who smoked and who did not smoke.

Given the relationship between the level of physical activity and energy expenditure and not consuming tobacco during adolescence, we believe it is necessary to implement sports promotion policies that encourage participation in physical activities. Likewise, we consider that it would be very interesting to develop health education programs at schools that equally approach adolescents' eating habits, level of physical activity and tobacco consumption. Such intervention should be prioritized in the case of girls given that they make up the group where tobacco consumption is most emergent and also the ones who do less physical exercise.

\section{CONCLUSIONS}

Significantly higher levels of physical exercise were observed in boys compared to girls, and both male and female adolescents have shown a significant association between the level of physical activity and not consuming tobacco. Only boys demonstrated a significant association between the energy expenditure resulting from physical exercise and not consuming tobacco.

\section{Acknowledgments}

To the entire faculty of the Secondary Education facilities where the survey took place. To the Education, Training and Labor Board for facilitating the authorization to conduct the study at the selected facilities. 


\section{REFERENCES}

1. Strauss RS, Pollack HA. Epidemic increase in childhood overweight, 1986-1998. JAMA 2001;286:2845-8.

2. Carta europea contra la Obesidad. Conferencia Ministerial Europea de la Organización Mundial de la Salud contra la obesidad. Estambul 2006 (Turquía). [Accessed on: June]. Available at: http://www.euro.who.int/en/what-wedo/health-topics/noncommunicable-diseases/obesity.

3. ReillyJJ,MethvenE,McDowellZC,Hacking B, etal. Health consequences of obesity. Arch Dis Child 2003;88:748-52.

4. Neumark-Sztainer D, Wall M, Larson NI, Eisenberg ME, et al. Dieting and disordered eating behaviors from adolescence to young adulthood: Findings from a 10-year longitudinal study. J Am Diet Assoc 2011;111:1004-11.

5. Van der Horst K, Oenema A, Van de Loij-Jansen P, Brug J. The ENDORSE study: research into environmental determinats of obesity related behaviors in Rotterdam schoolchildren. BMC Public Health 2008;8:142-51.

6. Artero EG, España-Romero V, Ortega FB, Jiménez-Pavón $\mathrm{D}$, etal.Health-related fitnessin adolescents: underweight, and not only overweight, as an influencing factor. The AVENA study. Scand J Med Sci Sports 2009;20:418-27.

7. Moreno LA, Mesana MI, González-Gross M, et al. Anthropometric body fat composition reference values in Spanish adolescents. The AVENA study. Eur J ClinNutr 2006;60:191-96.

8. Martínez F, Salcedo F, Rodríguez F, Gil CM, et al. Prevalencia de la obesidad y mantenimiento del estado ponderal tras un seguimiento de 6 años en niños y adolescentes: estudio CUENCA. Med Clin 2002;119:327-30.

9. Chatkin R, Chatkin JM. Smoking and changes in body weight: can physiopathology and genetics explain this association? J Bras Pneumol 2007;33:712-19.

10. Larson NL, Story M, Neumark-Sztainer D, Hannan PJ, et al. Are diet and physical activity patterns relationed to cigarette smoking in adolescents? Findings from project EAT. Prev Chronic Dis 2007;4:A51.

11. LaRowe TL, Piper ME, Schalm TR, Fiore MC, et al. Obesity and smoking: comparing cessation treatment seekers with the general smoking population. Obesity 2009;17:1301-5.

12. Hout I, Paradis G, Ledoux M. Factors associated with overweight and obesity in Quebec adults. Int J Obes Relat Metab Disord 2004;28:766-74.

13. Bradley DP, Jhonson LA, Zhang Z, Subar AF, et al. Effect of smoking status on total energy expenditure. J Nutr Metab 2010;7:81-6.

14. Encuesta estatal sobre el consumo de drogas en estudiantes deenseñanza secundaria(ESTUDES) 2010. [Accessed on:June 2012].Availableat:http://www.msc.es/novedades/docs / PRESENTACION_ESTUDES_2010.pdf

15. Aleixandre NL, Perello MJ, Palmer AL. Activity levels and drug use in a simple of Spanish adolescents. Addict Behav 2005;30:1597-2.

16. Wilson DB,Smith BN, Speizer IS, Bean MK, etal. Differences in food intake and exercise by smoking status in adolescents. Prev Med 2005;40:872-79.

17. Halperin AC, Smith SS, Heligenstein E, Brown D, et al. Cigarette smoking and associated health risk among students at five universities. Nicotine $\mathcal{E}$ Tobacco Research 2010;12:96-4.

18. Agencia Española de seguridad alimentaria. Estrategia NAOS. Actividad física en el niño y adolescente. 2005.
[Access: june 2012]. Available at: http: / / www. naos. aesan.mspsi.es/csym/alimentacion/categorias / categoria00006.html.

19. Casajus JA, Leiva MT, Villarroya A, Legaz A, et al. Physical performance and school physical education in overweight spanish children. Ann Nutr Metab 2007;51:288-96.

20. Haarens L, Deforche B, Maes L, Cardon G, et al. Physical activity and endurance in normal weight versus overweight boys and girls. J Sport Med Phys Fitness 2007;47:344-50.

21. Conelly JB, Duaso MJ, Butler G. A sistematic review of controlled trials of interventions to prevent childhood obesity and overweight: a realistic synthesis of the evidence. Public Health 2007;121:510-7.

22. Craig CL, Marshal AL, Sjostrom M, et al. International physical activity questionnaire: 12-country reliability and validity. Med Sci Sports Exerc 2003;35:1381-95.

23. Ainsworth BE, Haskell WL, Herrmann SD, Bauman AE, et al. 2011 Compendium of physical activities: a second update ofcodes and MET values. Med Sci Sports Exerc 2011;43:1575-81.

24. Brener ND, Kann L, Kinchen SA, Grunbaum JA, et al. Methodology of the youth risk behavior surveillance system. MMWR Recomm Rep 2004;53:1-13.

25. Colegio Oficial de Psicólogos. International Tests Comission. Directrices internacionales para el uso de los tests. Madrid: 2000. [Access: june 2012].Available at: http:// pendientedemigracion.ucm.es/info/psclinic/evaluacion/Documentos / DIRECTRICES\%20INTERNACIONALES $\% 20 \% 20$ PARA $\% 20$ EL $\% 20$ USO $\% 20$ DE $\% 20$ LOS $\% 20$ TESTS.pdf

26. Muñiz J. Directrices para la traducción y adaptación de los tests. Papeles del psicólogo 1996;66:63-0.

27. Cole TJ, Flegal KM, Nicholls D, Jackson AA. Body mass index cut offs to define thinness in children and adolescents: International survey. BMJ 2007;335:194-02.

28. Cano A, Pérez I, Casares I, Alberola S. Determinantes del nivel de actividad física en escolares y adolescentes: estudio OPACA. An Pediatr (Barc) 2011;74:15-4.

29. Thibault H, Contraed B, Saubusse E, Baine M, et al. Risk factors for overwight and obesity in French adolescents: Physical activity, sedentary behavior and parental characteristics. Nutrition 2010;26:192-00.

30. Villagrán S, Rodríguez A, Novalbos JP, Martínez JM, et al. Hábitos y estilos de vida modificables en niños con sobrepeso y obesidad. Nutr Hosp 2010;25:823-31.

31. Robles MI, Obando J, González MT, Bueno J. Asociación entre dieta, actividad física y consumo de tabaco en adolescentes. Semergen 2011;37:238-45.

32. Martínez-Gómez V, Martínez de Haro V, Del-Campo J, Zapatera B, et al. Validez de cuatro cuestionarios para valorar la actividad física en adolescentes españoles. Cac Sanit 2009;23:512-17.

33. Mulassi AH, Hadid C, Borracci RA, Labruma MC, et al. Hábitos de alimentación, actividad física, tabaquismo y consumo de alcohol en adolescentes escolarizados de la provincia y el conurbano bonaerenses. Arch Argent Pediatr 2010;108:45-4.

34. Janssen I, Katzmarzyk PT, Boyce WF, Vereecken C, et al. Comparison of overweight and obesity prevalence in school-aged youth from 34 countries and their relationships with physical activity and dietary patterns. Obesity 2005;6:123-32. 


\section{Annex 1}

The following questions are related to tobacco consumption.

We expect you to answer all questions.

1. How many of the people you know smoke on a regular basis? (indicate as many as you think necessary)

My father

My mother

My siblings

My boyfriend/girlfriend

My friends

Others (indicate who).

2. Have you ever smoked tobacco? (cigarettes, cigar or pipe; smoking means at least one cigarette, cigar or pipe, not just a puff or trying it)

Yes

No

\section{If you answered "No," skip to question 5}

3. At what age did you have your first cigarette? (cigarettes, cigar or pipe; smoking means at least one cigarette, cigar or pipe, not just a puff or trying it)

years old

4. In the past 30 days, how often have you smoked?

0 days

1-2 days

3-5 days

6-9 days

10-19 days

20-29 days

30 days
Below you will find a series of issues related to regular physical activity you do in your daily life.

Sports: "Sports" is defined both as physical activity (aerobics, footing, muscle-building, etc.) and sports (soccer, basketball, swimming, etc.) done out of school.

\section{REGULAR PHYSICAL ACTIVITY}

5. In the past 7 days, how often have you done intense physical exercise? days

If you answered "NO," skip to question 9

6. What sports or physical activity is it?

7. How often do you practice it on a weekly basis?
1-2 days
3 days
4 days
5 or more days

8. Approximately how many hours a day do you devote to practicing it?

30 minutes

30 minutes- 1 hour

1-2 hours

More than 2 hours

The following questions are related to some basic characteristics about you and your immediate environment.

We expect you to answer all questions.

9. What is your sex?

Man

Woman 
10. How old are you? years old

11. What grade are you in? $3^{\text {rd }}$ OSE

$4^{\text {th }}$ OSE

$1^{\text {st }}$ High School
12. How much money do you have available every week?

Less than 10 Euros

10-15 Euros

15-20 Euros

More than 20 Euros

13. At present, are you a member of a sports club?

Yes

No 